\title{
Doenças do sistema nervoso central em bovinos no Sul do Brasil ${ }^{1}$
}

\author{
Adrien Wilhelm Dilger Sanches ${ }^{2}$, Ingeborg Maria Langohr ${ }^{2}$, Adriana Lïcke Stigger ${ }^{2} \mathrm{e}$ \\ Claudio S.L. Barros ${ }^{3}$
}

\begin{abstract}
Sanches A.W.D., Langohr I.M., Stigger A.L. \& Barros C.S.L. 2000. [Diseases of the central nervous system in cattle of southern Brazil.] Doenças do sistema nervoso central em bovinos no Sul do Brasil. Pesquisa Veterinária Brasileira 20(3):113-118. Depto Patologia, Universidade Federal de Santa Maria, 97105-900 Santa Maria, RS, Brazil. E-mail: cslb@sm.conex.com.br

A retrospective study was carried out on 6,021 necropsies of cattle performed over a 36year period in southern Brazil. Of those, $552(9.16 \%)$ presented neurological clinical signs and their necropsy protocols were reviewed to gather information on type of gross and histopathological diagnosis, etiology, and clinical signs. In 147 cases (26.63\% of 552) there were no significant lesions in the central nervous system, in 79 (14.31\% of 552) no samples of nervous tissue were submitted to the laboratory and in 21 (3.81\% of 552) the tissues submitted were autolysed and not suitable for histological diagnosis. Lesions found in the remaining 305 cases were classified as inflammatory, degenerative, circulatory, congenital, and neoplastic. The inflammatory lesions accounted for the largest category ( $66.89 \%$ of 305 cases). This was further divided in lesions caused by viruses $(57.38 \%$ of 305 cases) and by bacteria $(9.51 \%$ of 305 cases). Diseases caused by viruses were rabies $(49.51 \%$ of 305 cases), necrotizing meningoencephalitis by bovine herpesvirus ( $4.59 \%$ of 305 cases), and malignant catarrhal fever $(3.28 \%$ of 305 cases). The degenerative changes were represented by 74 cases $(24.26 \%$ of 305 cases) and included status spongiosus due to liver failure induced by Senecio spp poisoning $(10.49 \%$ of 305 cases) or to the direct effect of poisoning by Ateleia glazioviana ( $0.33 \%$ of 305 cases); cases of liver failure not associated with morphological changes in the brain (2.95\% of 305 cases), myelomalacia due to cord compression (2.62\% of 305 cases), primary neuronal degeneration associated with Solanum fastigiatum poisoning (2.29\% of 305 cases); polioencephalomalacia ( $1.97 \%$ of 305 cases); tetanus $(1.31 \%$ of 305 cases) and intestinal coccidiosis in calves, ketosis, and botulism with one case each $(0.33 \%$ of 305 cases). Circulatory disturbances accounted for 19 cases $(6.23 \%$ of 305 cases) and included cerebral babesiosis $(5.57 \%$ of 305 cases) and hemorrhages due to trauma $(0.66 \%$ of 305 cases). Congenital conditions represented $2.29 \%$ of the 305 cases and included cerebelar abiotrophy (two cases) and one case each of porencephaly, hypomyelinogenesis, demyelination, hydrocephalus, and cerebellar malformation. Only one neuroectodermal neoplasm $(0.33 \%$ of 305 cases) was found in this series.
\end{abstract}

INDEX TERMS: Central nervous system, diseases of cattle, pathology.

\footnotetext{
${ }^{1}$ Aceito para publicação em 11 de abril de 2000.

Parte da dissertação de mestrado do primeiro autor. Defendida no Programa de Pós-Graduação em Medicina Veterinária, Área de Concentração em Patologia Veterinária, Centro de Ciências Rurais, Universidade Federal de Santa Maria (UFSM), em 14 de março de 2000.

${ }^{2}$ Programa de Pós-Graduação em Medicina Veterinária, Área de Concentração em Patologia Veterinária, Centro de Ciências Rurais, UFSM.

${ }^{3}$ Departamento de Patologia, UFSM, 97105-900 Santa Maria, Rio Grande do Sul, e-mail: cslb@sm.conex.com.br
}

RESUMO.- Um estudo retrospectivo foi realizado em 6.021 necropsias de bovinos realizadas num período de 36 anos no Sul do Brasil. Desses, 552 (9,16\%) apresentaram sinais clínicos de distúrbios nervosos e seus protocolos foram revisados para colher informações sobre os diagnósticos macro e microscópicos, etiologia e sinais clínicos. Em 147 casos (26,63\% de 552$)$ não havia lesões significativas no sistema nervoso central, em $79(14,31 \%$ de 552$)$ o sistema nervoso não havia sido enviado e em 21 (3,81\% de 552) os tecidos 
foram submetidos autolisados, apresentando-se impróprios para o diagnóstico histológico. As lesões encontradas nos restantes 305 casos foram classificadas como inflamatórias, degenerativas, circulatórias, congênitas e neoplásicas. As lesões inflamatórias constituíram a maior categoria $(66,89 \%$ de 305 casos). Essa categoria foi subdividida em lesões inflamatórias produzidas por vírus $(57,38 \%$ de 305 casos) e por bactérias $(9,51 \%$ de 305 casos). As três doenças causadas por vírus foram raiva $(49,51 \%$ de 305 casos), meningoencefalite necrosante por herpesvírus bovino $(4,59 \%$ de 305 casos) e febre catarral maligna ( $3,28 \%$ de 305 casos). As alterações degenerativas foram representadas por 74 casos $(24,26 \%$ de 305 casos). Condições incluídas nessa categoria foram status spongiosus causado por insuficiência hepática relacionada à intoxicação por Senecio spp (10,49\% de 305 casos) ou ao efeito direto da intoxicação por Ateleia glazioviana $(0,33 \%$ de 305 casos), casos de insuficiência hepática sem alterações morfológicas no cérebro (2,95\% de 305 casos), mielomalácia por compressão da medula (2,62\% de 305 casos), degeneração neuronal primária na intoxicação por Solanum fastigiatum (2,29\% de 305 casos), polioencefalomalácia $(1,97 \%$ de 305 casos), tétano (1,31\% de 305 casos) e coccidiose intestinal em terneiros, cetose e botulismo com um caso cada $(0,33 \%$ de 305 casos). Alterações circulatórias foram representadas por 19 casos (6,23\% de 305 casos) e incluíram babesiose cerebral (5,57\% de 305 casos) e hemorragias devidas a trauma $(0,66 \%$ de 305 casos). As alterações congênitas representaram 2,29\% dos 305 casos e consistiram de abiotrofia cerebelar ( 2 casos), porencefalia, hipomielinogênese, desmielinização, hidrocefalia, e malformação cerebelar ( 1 caso cada). Apenas uma neoplasia neuroectodérmica $(0,33 \%$ de 305 casos) foi encontrada nessa série.

TERMOS DE INDEXAÇÃO: Sistema nervoso central, doenças de bovinos, patologia.

\section{INTRODUÇÃO}

Os distúrbios do sistema nervoso central (SNC) em bovinos abrangem um grupo de enfermidades importantes. Somente a raiva bovina é responsabilizada, em todo o mundo, por uma perda anual de cerca de 50 milhões de dólares (King \& Turner 1993). A importância dessas enfermidades cresceu desde o aparecimento, em 1985-86, da encefalopatia espongiforme dos bovinos (BSE) (Wells et al. 1987) e sua importância política, social e de saúde pública foi ainda mais salientada, quando a BSE foi relacionada ao aparecimento de uma nova variante da doença humana CJD (Creutzfeldt-Jakob disease) na Inglaterra (Will et al. 1996, Almond \& Pattison 1997). Por causa disso, autoridades sanitárias internacionais estão solicitando dos países exportadores de carne, como é o caso do Brasil, que apresentem evidências de que seus rebanhos são livres de BSE. Isso equivale a dizer que os países devem estar capacitados a identificar as outras doenças que afetam o SNC de bovinos, mesmo na ausência de casos de BSE.

O Laboratório de Patologia Veterinária (LPV) do Departamento de Patologia da Universidade Federal de Santa Maria, a exemplo de outros laboratórios de diagnóstico no país, vem diagnosticando doenças em animais há vários anos. Neste trabalho todas as doenças do SNC de bovinos diagnosticadas no LPV nos últimos 36 anos foram revisadas.

\section{MATERIAL E MÉTODOS}

Os protocolos de necropsia e de histopatologia do arquivo do Laboratório de Patologia Veterinária (LPV) do Departamento de Patologia da Universidade Federal de Santa Maria foram revisados. Os protocolos de necropsia constam 1) das descrições macroscópicas e microscópicas das necropsias realizadas no LPV ou a campo, por docentes e estagiários/pós-graduandos do LPV e 2) das descrições macroscópicas e microscópicas de material de necropsias realizadas por outros veterinários e enviado ao LPV. Na revisão, anotou-se o número total de bovinos examinados $(1+2)$ e o número de bovinos examinados com sinais clínicos de distúrbios nervosos no período de 1964 a 1999 (inclusive). Para os bovinos com sinais clínicos de distúrbios nervosos, foi anotado o seguinte: número do protocolo, idade do animal, sexo, procedência, data de ocorrência do caso, diagnóstico morfológico, diagnóstico etiológico e descrições macro e microscópica. Na maioria dos casos, o material havia sido examinado em microscopia óptica na coloração de hematoxilina e eosina. Ocasionalmente, colorações especiais como "Luxol Fast Blue", Ziehl-Neelsen e Giemsa foram também utilizadas. Em duas ocasiões, descrições de microscopia eletrônica haviam sido adicionadas ao caso com objetivo de diagnóstico de rotina.

\section{RESULTADOS}

De janeiro de 1964 a dezembro de 1999 foram examinados materiais de necropsia de 6.021 bovinos. Desses, $552(9,16 \%)$ tinham histórico de sinais clínicos de distúrbios nervosos. Os detalhes com que esses sinais clínicos foram anotados nos protocolos eram variáveis. Por vezes, constavam apenas de expressões como "sinais nervosos", "sinais de encefalite" e "suspeito de raiva". Em 147 dos casos (26,63\% dos bovinos com sinais clínicos de distúrbios nervosos), as lesões estavam ausentes, foram pouco significativas para explicar os sinais clínicos ou foram consideradas artefatos. Em 79 casos $(14,31 \%$ dos bovinos com sinais clínicos de distúrbios nervosos), o sistema nervoso não foi enviado ao laboratório, excluindo a possibilidade de diagnóstico. Em 21 casos (3,81\% dos bovinos com sinais clínicos de distúrbios nervosos), o material era impróprio (autólise) para exame histológico.

Para efeitos de descrição, as lesões dos 305 casos em que foi possível se concluir um diagnóstico foram classificadas como inflamatórias, degenerativas, circulatórias, congênitas e neoplásicas (Quadro 1). Casos em que o diagnóstico foi estabelecido, mesmo na ausência de alterações morfológicas no sistema nervoso central (SNC), como intoxicação por Claviceps paspali, tétano, botulismo, coccidiose intestinal, cetose, febre vitular e manifestação neurológica associada à lesão hepática aguda, foram arbitrariamente classificados no grupo das alterações degenerativas.

\section{Alterações inflamatórias produzidas por vírus}

Cento e setenta e cinco casos $(57,38 \%$ de 305$)$ consistiram de doenças atribuídas a vírus. Cento e cinqüenta e um casos casos $(49,51 \%$ de 305$)$ foram diagnosticados como raiva. Nesses, as lesões consistiam de meningoencefalite não purulen- 
ta caracterizada por infiltrado inflamatório mononuclear nas meninges e nos espaços perivasculares de Virchow-Robin. Critérios adicionais, ocasionalmente presentes, incluíam microgliose focal ou difusa, mas sem necrose neuronal. Alguns desses casos eram associados à inflamação do gânglio

Quadro 1. Diagnósticos neuropatológicos em 305 bovinos com sinais clínicos de distúrbios nervosos

\begin{tabular}{|c|c|c|}
\hline Diagnóstico & $\begin{array}{l}\text { Número } \\
\text { de } \\
\text { animais }\end{array}$ & $\%$ \\
\hline Alterações inflamatórias a vírus & 175 & 57,38 \\
\hline Raiva & 151 & 49,51 \\
\hline Meningoencefalite necrosante (BHV-5) ${ }^{\mathrm{a}}$ & 14 & 4,59 \\
\hline Febre catarral maligna & 10 & 3,28 \\
\hline Alterações inflamatórias por bactérias & 29 & 9,51 \\
\hline Leptomeningite fibrinopurulenta em terneiros & 13 & 4,27 \\
\hline $\begin{array}{l}\text { Leptomeningite purulenta e abscessos secundários a } \\
\text { osteomielite, por extensão ou via hematógena. }\end{array}$ & 10 & 3,28 \\
\hline Meningoencefalite bulbar com microabscessos (listeriose) & 3 & 0,98 \\
\hline Meningite e meningoencefalite granulomatosas (tuberculose) & e) 3 & 0,98 \\
\hline Alterações degenerativas & 74 & 24,26 \\
\hline Status spongiosus, intoxicação por Senecio spp & 32 & 10,49 \\
\hline Encefalopatia hepática sem lesões encefálicas determinadas & 9 & 2,95 \\
\hline Mielomalácia por compressão medular & 8 & 2,62 \\
\hline $\begin{array}{l}\text { Degeneração e perda de neurônios de Purkinje (intoxicação } \\
\text { por Solanum fastigiatum) }\end{array}$ & 7 & 2,29 \\
\hline Polioencefalomalácia & 6 & 1,97 \\
\hline Tétano & 4 & 1,31 \\
\hline Intoxicação por Claviceps paspali & 3 & 0,98 \\
\hline Coccidiose intestinal em terneiros & 1 & 0,33 \\
\hline Cetose & 1 & 0,33 \\
\hline Febre vitular & 1 & 0,33 \\
\hline Botulismo & 1 & 0,33 \\
\hline Status spongiosus (intoxicação por Ateleia glazioviana) & 1 & 0,33 \\
\hline Alterações circulatórias & 19 & 6,23 \\
\hline Babesiose cerebral & 17 & 5,57 \\
\hline Hemorragia causada por traumatismo & 2 & 0,66 \\
\hline Alterações congênitas & 7 & 2,29 \\
\hline Alterações neoplásicas & 1 & 0,33 \\
\hline Ependimoma & 1 & 0,33 \\
\hline Total & 305 & 100 \\
\hline
\end{tabular}

aBHV-5 = herpesvírus bovino 5.

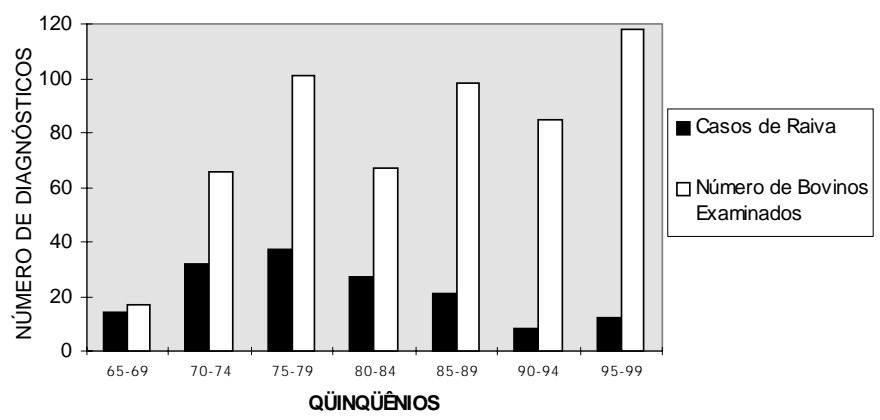

Fig. 1. Distribuição dos casos de raiva em 552 bovinos com sinais clínicos de distúrbios nervosos. Os casos foram agrupados por qüinqüênios. $O$ ano de 1964, em que não houve registro de caso, não foi incluído. de Gasser. Em 55 casos desse grupo, o diagnóstico de raiva foi confirmado pela visualização do corpúsculo de Negri, pela imunofluorescência e/ou inoculação em camundongos. Embora em 96 casos, o diagnóstico de raiva não tenha sido tentado por outros meios além da histopatologia, as características clínicas e morfológicas eram suficientemente semelhantes aos outros 55 casos para incluí-los dentro dessa etiologia. Os principais sinais clínicos apresentados pelos bovinos desse grupo foram sialorréia, olhar fixo, midríase, incoordenação motora progressiva e perda de sensibilidade e paralisia, principalmente dos membros pélvicos, tremores musculares, perda de sensibilidade e tônus da cauda e do ânus, com relaxamento do esfíncter anal. A evolução foi de 4-7 dias. A Fig. 1 mostra o total dos 151 casos de bovinos com raiva, distribuídos por qüinquiênios durante todo o período do levantamento.

Quatorze casos (4,59\% de 305$)$ foram diagnosticados como meningoencefalite necrosante. Em quatro desses casos a etiologia foi confirmada (por cultura, hibridização in situ e análise de restrição) como herpesvírus bovino 5 (BHV-5). Em um outro caso, partículas víricas características foram observadas por microscopia eletrônica no núcleo de células do SNC, provavelmente astrócitos. Como os aspectos epidemiológicos, clínicos e morfológicos foram semelhantes nos outros nove casos, eles foram também considerados dentro dessa etiologia. Essa doença ocorreu principalmente em terneiros com idades até 18 meses, mas afetou uma novilha de 2 anos e também vacas adultas (4-5 anos). Os principais sinais clínicos associados à enfermidade consistiam de depressão, febre $\left(40^{\circ}-41^{\circ} \mathrm{C}\right)$, incapacidade de deglutir, ranger de dentes, rigidez da mandíbula, tremores musculares, andar em círculos, incoordenação motora, cegueira, sialorréia, opistótono, flacidez da língua, decúbito e morte. 0 curso clínico foi de 57 dias. As lesões histológicas consistiam de infiltrado inflamatório mononuclear nas meninges e no espaço perivascular, associado a vasculite, necrose neuronal, edema perineuronal e da substância branca, gliose multifocal e, ocasionalmente, inclusões intranucleares eosinofílicas em astrócitos e neurônios.

Dez casos $(3,28 \%$ de 305$)$ tinham o diagnóstico de febre catarral maligna (FCM). A vasculite era o aspecto característico das lesões no SNC. Células mononucleares (linfócitos e histiócitos) infiltravam a média e a adventícia das artérias e, muitas vezes, apareciam nos espaços de Virchow-Robin. Em dois casos havia também meningite fibrinosa. Lesões características em outros órgãos ajudaram a confirmar o diagnóstico. Os sinais clínicos mais freqüentemente associados à $\mathrm{FCM}$ inclúam incoordenação motora, tremores musculares, cegueira e movimentos de pedaleio quando em decúbito.

Alterações inflamatórias produzidas por bactérias

As lesões atribuídas a agentes bacterianos somaram 29 casos (9,51\% de 305). Essas lesões se caracterizaram por exsudato purulento, fibrinopurulento ou granulomatoso e afetavam as leptomeninges ou o plexo coróide. Em casos de abscessos, as lesões foram vistas no parênquima encefálico.

Em 13 casos (4,27\% de 305), as lesões de leptomeningite 
ou plexocoroidite ocorreram em terneiros com idades entre 5 dias e 3 meses. Essas lesões eram ocasionalmente associadas a processos inflamatórios purulentos ou fibrinopurulentos em outros locais, como abscessos da pituitária, artrite, e oftalmite. Em 10 casos (3,28\% de 305), as lesões ocorreram em bovinos adultos e consistiam de abscessos metastáticos, originários de processos purulentos em outros locais do organismo ou por extensão de processos vizinhos ao SNC, como osteomielite. Os sinais clínicos associados a essas inflamações foram variáveis, dependendo do local da lesão. Culturas raramente foram tentadas, mas Escherichia coli foi isolada de um caso em terneiros e Arcanobacter (Actinomyces) pyogenes de um abscesso em um bovino adulto.

Encefalite do tronco encefálico, caracterizada por microabscessos e infiltrados perivasculares mononucleares e focos de gliose, ocorreu em três bovinos $(0,98 \%$ de 305$)$. Embora as lesões sejam típicas de listeriose, em nenhum dos casos foi tentado o cultivo de Listeria monocytogenes. Em um desses casos, as alterações, com distribuição idêntica, eram acrescidas de macrófagos espumosos ("gitter cells") o que caracteriza um estágio mais crônico dessa enfermidade. Os três casos de listeriose registrados ocorreram na primavera. Em um deles, foi estabelecida uma relação com consumo de silagem, mas isso não foi possível nos outros dois casos. Os animais com listeriose eram adultos jovens (2-3 anos) e os sinais clínicos relatados consistiram de midríase, sialorréia, opistótono, paralisia da língua e dos músculos da face, tremores, disfagia, cegueira, andar em círculos e incoordenação dos membros pélvicos.

Tuberculose foi diagnosticada em três casos $(0,98 \%$ de 305$)$. As lesões ocorriam nas meninges ou no parênquima do cérebro e consistiam de granulomas caseocalcários com células gigantes tipo Langhans. Bacilos álcool-ácido-resistentes foram observados na coloração de Ziehl-Neelsen. No único caso em que os sinais clínicos foram registrados observou-se incoordenação motora, andar em círculos, cegueira, opistótono, convulsões, paralisia da porção posterior do corpo e decúbito.

\section{Alterações degenerativas}

As alterações de 74 casos $(24,26 \%$ de 305$)$ foram classificados como degenerativas. A etiologia desses casos incluía distúrbios relacionados a insuficiências hepáticas, intoxicações por plantas e micotoxinas (S. fastigiatum, C. paspali), compressão medular (por osteomielite de corpo de vértebra, abscessos do canal medular), causas metabólicas e nutricionais (polioencefalomalácia, cetose, febre vitular) e toxinfeç̧ões (botulismo, tétano). Botulismo é uma alteração do sistema nervoso periférico, mas é freqüientemente confundida com doenças primárias do SNC.

A alteração degenerativa mais freqüente foi status spongiosus, observado em 33 casos de alterações degenerativas. Em todos os casos essa alteração era edema intramielínico e mais freqüiente na substância branca da medular do cerebelo, nos pedúnculos cerebelares, no tronco encefálico e no limite entre a substância branca subcortical e córtex telencefálico. Em 32 casos (10,49\% de 305), era secundário à insuficiência hepática crônica (encefalopatia hepática) associada à intoxicação por Senecio spp. Sinais clínicos inclúam agressividade, tremores musculares, incoordenação motora e cegueira, andar em círculos e pressão da cabeça contra objetos. Em apenas um caso o status spongiosus foi considerado primário do SNC (não havia lesão hepática) e causado pela ingestão de Ateleia glazioviana. Nesse caso, o sinal clínico predominante era de letargia. Em nove casos (2,95\% de 305) de doença hepática aguda de origem tóxica (por exemplo, intoxicação por Xanthium sp) não havia alterações morfológicas no SNC.

\section{Alterações circulatórias}

Dezenove casos $(6,23 \%$ de 305$)$ foram incluídos nessa categoria. Babesiose com manifestação de distúrbios nervosos (forma cerebral da babesiose) foi diagnosticada em 17 casos $(5,57 \%$ de 305$)$. Animais com essa alteração mostravam sinais clínicos de encefalite como convulsões, opistótono e tremores. Macroscopicamente havia avermelhamento (cor cereja) dos córtices telencefálico e cerebelar. Esfregaços do córtex telencefálico corados pelo Giemsa revelavam grande número de eritrócitos parasitados por Babesia bovis preenchendo a luz vascular. Microscopicamente havia estase e seqüestro eritrocitário intravascular e edema perivascular e perineuronal. Hemorragia subdural causada por trauma ao SNC foi diagnosticada em dois casos $(0,66 \%$ de 305$)$.

\section{Alterações congênitas}

Sete casos de alterações congênitas $(2,29 \%$ de 305$)$ foram observados. Afetaram terneiros de 1 dia a 6 meses de idade e incluíam abiotrofia cerebelar ( 2 casos), porencefalia, hipomielinogênese, desmielinização, hidrocefalia e malformação cerebelar (1 caso cada). A etiologia não foi estabelecida. Os casos de hipomielinogênese afetaram $24 \%$ $(12 / 50)$ dos terneiros de um estabelecimento. Apenas um foi necropsiado. Os sinais clínicos apareciam desde o nascimento e consistiam de incoordenação, fraqueza muscular e incapacidade para mamar. Microscopicamente havia déficit de mielina confirmado pela coloração de "Luxol Fast Blue". No caso de malformação cerebelar, quatro terneiros foram afetados (um necropsiado). Os sinais clínicos eram de ataxia e estavam presentes desde o nascimento. Casos de aborto foram também registrados neste rebanho. No caso examinado havia agenesia do verme cerebelar e moderada hidrocefalia.

\section{Alterações neoplásicas}

Um ependimoma $(0,33 \%$ de 305$)$ foi o único tumor encontrado. Ocorreu numa vaca Holandês Preto e Branco de 7 anos de idade que apresentou emagrecimento e déficit visual progressivos por alguns meses. Macroscopicamente, observouse uma massa arredondada de $3-5 \mathrm{~cm}$ de diâmetro, com limites imprecisos obstruindo o terceiro ventrículo e o aqueduto mesencefálico.

\section{DISCUSSÃO}

Neste estudo, aproximadamente $10 \%$ dos 6.021 bovinos necropsiados apresentavam sinais clínicos de distúrbios nervosos, o que indica que enfermidades do sistema nervoso 
são importantes nessa espécie. Quase a totalidade dos casos deste estudo é originária do Rio Grande do Sul. A população bovina do estado está em torno de 13 milhões de cabeças e a mortalidade anual é estimada em 5\%, correspondendo a 650.000 bovinos em números absolutos. ${ }^{4}$ Considerando que $10 \%$ morrem em consequiência de alterações associadas a distúrbios nervosos ( 65.000 bovinos) e considerando o valor médio de R\$ 170,00/bovino, há uma perda direta anual ao redor de 11 milhões de reais em consequiência dessas enfermidades. Essas cifras são ainda pequenas quando comparadas às de outro estudo semelhante realizado no Mato Grosso do Sul em 996 bovinos necropsiados (Lemos et al. 1998), em que as enfermidades com distúrbios nervosos corresponderam a $47,38 \%$ dos bovinos necropsiados. As enfermidades relatadas por esses autores são essencialmente as mesmas (embora em proporções diferentes) que as encontradas neste estudo e em outro publicado no Rio Grande do Sul (Riet-Correa et al. 1998). Isso permite sugerir que as doenças relatadas neste estudo são representativas das encontradas em outros estados do Brasil. As diferenças devem estar na incidência de cada uma dessas doenças e no aparecimento de algumas doenças de origem tóxica (principalmente intoxicações por plantas) e metabólicas, peculiares para cada região. Por exemplo, o botulismo é responsável por 33\% das doenças nervosas em bovinos no Mato Grosso do Sul (Lemos et al. 1998) e por apenas $0,33 \%$ em nosso levantamento. Outros fatores, além da evidente variabilidade na incidência regional da doença, podem contribuir para essa diferença, uma vez que o botulismo deve ser diagnosticado a campo, pelos sinais clínicos ou por exames laboratoriais específicos e não pode ser diagnosticado apenas em amostras de cérebro enviadas ao laboratório.

Cento e quarenta e sete casos $(26,63 \%$ dos bovinos com sinais clínicos de distúrbios nervosos) não apresentaram alterações no sistema nervoso central (SNC), ficando, portanto, sem diagnóstico. Esse número é alto, mas em estudos semelhantes realizados na Inglaterra em 200 bovinos (McGill \& Wells 1993) e na Escócia em 225 bovinos (Jeffrey 1992), os casos sem diagnóstico (devido à ausência de lesões no SNC) foram respectivamente de $57,5 \%$ e $43,11 \%$ dos bovinos com sinais clínicos de distúrbios nervosos. Considerações sobre a etiologia desses 147 casos só podem ser especulativas. Uma parte deles pode ser de doenças metabólicas, como cetose e febre vitular, intoxicações (Claviceps paspali) e toxinfecções (botulismo, tétano) onde as alterações morfológicas do SNC são mínimas ou ausentes. Nesses casos, o exame clínico a campo e o estudo da epidemiologia são abordagens essenciais para o diagnóstico. Outra possível explicação para esses casos é que, às vezes, os sinais clínicos são mal interpretados como distúrbios neurológicos. Isso ocorre principalmente em doenças musculares com distúrbios da locomoção (por exemplo, intoxicações por Senna occidentalis ou por antibióticos ionóforos). Além disso, o temor compreensível que as pessoas têm, em geral, de contrair raiva, leva à remessa do cérebro para exame mesmo que os sinais clínicos não sejam de dis-

${ }^{4}$ Dados da Secretaria de Agricultura do Estado do Rio Grande do Sul. túrbios nervosos. Em vários casos deste levantamento havia apenas a anotação "suspeito de raiva" no histórico clínico.

Apenas três enfermidades virais foram identificadas: raiva, meningoencefalite necrosante por herpesvírus bovino e febre catarral malígna. As alterações encefálicas dessas três doenças são morfologicamente distintas.

Observou-se que os casos de raiva aumentaram a partir do início da década de 70 até meados da década de 80 , com progressivo decréscimo desde então. Esse decréscimo deveuse, provavelmente, ao combate de morcegos na região. Os poucos casos registrados de 1965 a 1969 refletem o menor número de materiais enviados naquela época.

Apenas três casos de listeriose encefálica foram identificados. Os diagnósticos de listeriose neste estudo basearamse nos achados morfológicos característicos. Essa abordagem diagnóstica pode ser discutível, mas as lesões da doença são características e permitem um diagnóstico razoavelmente acurado. Os dados tendem a indicar, pelo menos, que a listeriose é uma enfermidade pouco freqüente no estado. A doença é descrita como ocorrendo no inverno, em países de clima frio e é associada à alimentação com silagem de má qualidade (Schneider 1994). Nos casos verificados neste estudo, apenas um bovino estava sendo alimentado com silagem e todos os três casos ocorreram na primavera.

Uma alteração freqüiente encontrada no encéfalo dos bovinos foi a de degeneração esponjosa (status spongiosus) do cérebro. Quase todos eles (32/33) ocorreram em consequiência de insuficiência hepática (encefalopatia hepática) associada à intoxicação por Senecio spp. Em 9 casos de insuficiência hepática havia sinais clínicos de doença nervosa, mas não havia alterações morfológicas no SNC. Situação semelhante tem sido descrita na intoxicação espontânea por Xanthium cavanillesii em bovinos (Driemeier et al. 1999) e experimental em ovinos (Loretti et al. 1999). Esses autores sugerem que talvez outros mecanismos, como a hipoglicemia que ocorre nessas intoxicações, possam ser responsáveis pelos sinais clínicos.

Em 17 casos, os sinais clínicos de distúrbios nervosos foram produzidos pela forma cerebral de Babesia bovis. A babesiose bovina é uma doença comum no Rio Grande do Sul e suas manifestações nervosas devem ser consideradas no diagnóstico diferencial das doenças do SNC nessa espécie. Os sinais clínicos são causados por edema cerebral induzido pelo seqüestro de eritrócitos nos capilares da substância cinzenta do cérebro (Everitt et al. 1986). Esse seqüestro eritrocitário produz uma coloração cereja da substância cinzenta do cérebro e cerebelo que é característica da babesiose cerebral induzida em bovinos por $B$. bovis. Os sinais clínicos associados à acentuada infecção intestinal por Eimeria sp parecem ser induzidos pela ação sobre o SNC de uma toxina secretada pelos protozoários (Jubb \& Huxtable 1993). Nesses casos não há alterações morfológicas no SNC.

Um ependimoma ( $0,33 \%$ de 305 casos) foi o único tumor encontrado neste levantamento. Embora esse achado corrobore a noção geral de que neoplasias são achados pouco comuns no SNC de bovinos, no levantamento da Inglaterra (McGill \& Wells 1993) foram observados 5 casos (2,5\%) e no 
da Escócia (Jeffrey 1992), 4 casos $(1,77 \%)$ de neoplasias primárias do SNC.

Casos de alterações congênitas ocorreram esporadicamente. O histórico clínico, a epidemiologia e as alterações morfológicas do caso de hipomielinogênese são semelhantes aos descritos anteriormente no Rio Grande do Sul (Riet-Correa et al. 1998). Esses autores encontraram níveis baixos de cobre no fígado e SNC dos animais afetados e sugeriram deficiência de cobre como etiologia. Os casos de hipomielinogênese e malformação cerebelar descritos aqui têm aspectos epidemiológicos e morfológicos da infecção in utero pelo vírus da diarréia viral bovina (Jubb \& Huxtable 1993), mas a etiologia não foi confirmada.

Em nenhum caso, mesmo nos 147 sem diagnóstico, foram observadas lesões que pudessem ser interpretadas como as descritas para encefalopatia espongiforme bovina (Wells et al. 1987).

\section{REFERÊNCIAS}

Almond J. \& Pattison J. 1997. Human BSE. Nature 389:437-438.

Driemeier D., Irigoyen L.F., Loretti A.P., Colodel E.M. \& Barros C.S.L. 1999. Intoxicação espontânea pelos frutos de Xanthium cavanillesii (Asteraceae) em bovinos. Pesq. Vet. Bras. 19:12-18.

Everitt J.I., Shadduck J.A., Steinkamp C. \& Clabaugh G. 1986. Experimental Babesia bovis infection in Holstein calves. Vet. Pathol. 23:556-562.

Jeffrey M. 1992. A neuropathological survey of brains submitted under the bovine spongiform encephalopathy orders in Scotland. Vet. Rec. 131:332337.
Jubb K.V.F. \& Huxtable C.R. 1993. The nervous system, p. 267-439. In: Jubb K.V.F., Kennedy P. C. \& Palmer N. (ed.) Pathology of Domestic Animals. Vol. 1. 4th ed. Academic Press, San Diego. 780 p.

King A. A. \& Turner G.S. 1993. Rabies: A review. J. Comp. Path. 108:1-39.

Lemos R.A.A., Brum K.B., Bernardo K.C., Katayama K.A., Mori A.E., Bonilha M.M. \& Cavallero J.C.M. 1998. Aspectos epidemiológicos das principais enfermidades caracterizadas por sintomatologia nervosa em bovinos, diagnosticadas no Mato Grosso do Sul. Universidade Federal de Mato Grosso do Sul, Campo Grande. Relatório de Bolsa de Iniciação Científica do CNPq. $16 \mathrm{p}$.

Loretti A.P., Bezerra P.S., Ilha M.R.S., Barros S.S. \& Barros C.S.L. 1999. Intoxicação experimental pelos frutos de Xanthium cavanillesii (Asteraceae) em ovinos. Pesq. Vet. Bras. 19:71-78.

McGill, I.S. \& Wells, G.A.H. 1993. Neuropathological findings in cattle with clinically suspect but histologically unconfirmed bovine spongiform encephalopathy (BSE). J. Comp. Pathol. 108:241-260.

Riet-Correa F. Schild A.L. \& Fernandes C.G. 1998. Enfermidades do sistema nervoso dos ruminantes no sul do Rio Grande do Sul. Ciência Rural 28:341348.

Schneider D. J. 1994. Listeriosis, p. 1374-1377. In: Coetzer J.A.W., Thomson G.R. \& Tustin, R. C. (ed.) Infectious Diseases of Livestock with Special Reference to Southern Africa. Vol. 2. Oxford University Press, Cape Town. $1605 \mathrm{p}$.

Wells G.A.H., Scott A.C., Johnson C.T., Gunning R.F., Hancock R. D., Jeffrey M., Dawson M. \& Bradley R. 1987. A novel progressive spongiform encephalopathy in cattle. Vet. Rec. 121:419-420.

Will R.G., Ironside J. W., Zeidler M., Cousens S. N., Estibeiro K., Alpeovitch A., Poser S., Pocchiari M., Hofman, A. \& Smith P.G. 1996 A new variant of Creutzfeldt-Jakob disease in the UK. Lancet 347:921-925. 